\title{
TESTS OF DEFORMATION AND TENSIONS IN REINFORCED NON-COHESIVE SOIL LAYER
}

The paper describes the results of laboratory testing of vertical deformations, horizontal pressure and vertical tensions on the close contact between reinforced non-cohesive soil layer and single-parameter subsoil. In particular, the diagrams of deformations and vertical tensions have been presented in the function of static load and reinforcement parameters. The following parameters have been also formulated: pattern to the calculation of coefficient of vertical tensions remittance and condition of equilibrium tensions in the reinforced soil model.

\section{Introduction}

The subject under analysis is the work of statically loaded soil layer reinforced with horizontal plates, on the basis of carried out testing [5-9]. The models considered constitute an analogue of pavement or road foundation, in relation to which they include non-cohesive soil layer (river sand of medium-size graining, valley gravel $5 / 10$, basalt grit $8 / 16$ and basalt breakstone). The problem of the connection between horizontal and vertical deformations has been discussed, and the attention was focused on the distribution and values of vertical pressures of the models considered on the single-parameter Winkler-type subsoil.

The scope of considerations comprises the following issues:

- horizontal and vertical deformations, and vertical tensions on the contact between soil layer (reinforcement with unwoven fabric) and subsoil;

- deformation of soil layer reinforced with geogrids;

- formulation of the tension equilibrium condition, expressing the relation between vertical pressures of loaded soil layer and horizontal deformations, in conditions of a laboratory model.

\section{Remarks to the testing method}

The modelled soil layer (soil sample) is placed in a test container, whose parameters were characterised in publications [5-9]. Assuming the unidirectional work of the plates, e.g. as strings stretched along the axis, it is enough to accept the reinforcement in the form of flat bars arranged in the direction of the occurrence of tensile forces. The task of the reinforcement consists in partial taking over of horizontal forces of lateral pressure caused by tension from soil vertical load $[1,3,4]$. Due to this, the horizontally placed reinforcement was accepted, i.e. perpendicular to the plane of loading. The soil sample (model) considered is in the spatial state of tension and deformation. Therefore, for the reason of the direc- tions of horizontal forces action, a suitable form of reinforcement may be: mat, grate or grid. Reinforcement of this type can be moulded out of flat bars or rods in the geometrical arrangement of a grid with rectangular or square meshes. The structure of the container enables axial symmetry of load and deformation of the examined soil sample. Taking into account the orthogonal character of the directions of main tensions, reinforcement in the form of grids with straight weave was used in principle, in directions corresponding to the directions of the main axes in the ratio to the container horizontal projection. Generally, the following components were used as reinforcement: steel grids; ordinary plastic grids; plastic grids with tensile strength comparable to steel (the so-called geogrids); geotextile mats (unwoven fabric of Polish and Czech manufacturing) [5-9].

\section{Protective layer of soil reinforced with unwoven fabrics}

The laboratory testing project and the scheme of sand samples reinforced with unwoven fabrics: Polish WD-EB and Czech Terratex 600 are included in publication [7].

Figure 1 presents charts of horizontal pressures of sand samples with triple unwoven fabric reinforcement, in the function of its location. The figures presented above concern sample load $q=0,19$ $\mathrm{Mpa}$. The value of total pressure for the standard (sample with no reinforcement) was accepted as $P_{y}=100 \%$. Total lateral pressure in proportional relation in the standard ratio was calculated identically as in case of samples reinforced with openwork plates.

As a result of its structure, the unwoven fabric (geotextile mat), totally delaminates soil, therefore the conditions of its work are different than of a grid, i.e. an openrork plane. Moreover, the unwoven fabric is a significantly deformable material. Soil co-operation with this type of plate is possible in the form of friction. The soil mass movement caused by deformations as an effect of load

\footnotetext{
* Andrzej Surowiecki ${ }^{1}$, Edward Hutnik ${ }^{2}$

${ }^{1}$ Technical University of Wrocław, Institute of Civil Engineering; Agricultural University in Wrocław, Institute of Building and Landscape Architecture.

${ }^{2}$ Agricultural University in Wrocław, Institute of Building and Landscape Architecture.
} 
is possible only along the mat surface. As for vertical relocations of soil grains situated on the contact with the mat, they are possible as a result of vertical deformations of the unwoven fabric, i.e. local deflections after the formation of a central trough or as a consequence of total settlement of the geosynthetic plane. As an effect of loading, the mat mainly considerably deforms and settles together with the soil overlay. The value of settlement depends, among others, on the plate location in the soil sample.

One can draw a conclusion from the experimental tests as to the functioning of two phases of geo-unwoven fabric, in the mechanical sense:

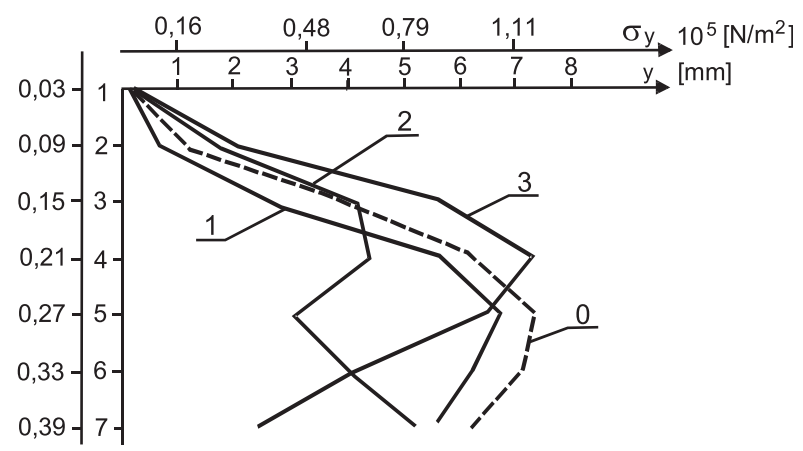

Phase I - mat settlement (vertical relocation) with loaded soil overlay. Phase II - partial transmission of tensile forces from the soil layer, in the form of friction.

Fig. 1 Lateral pressure of sand samples reinforced with triple unwoven Terratex 600 in the function of changeable location [5]: $a$ - cycle I of load; $b$ - cycle IX; 0 - standard; 1 - unwoven fabric Terratex 600 on the level $z_{2} ; 2$ - on the level $z_{4} ; 3$ - on the level $z_{6}$.

In this phase, the unwoven fabric undergoes purposeful deformation in the form of a central trough. Moreover, the expected vertical deformation of the mat takes place, consisting in the collapse (pressing) of the mat plane under the influence of vertical constituent tensions. The unwoven fabric stretching was observed. The increase of $\Delta L$ length ( $\mathrm{L}$ is the length and width of the square surface of the mat used for reported tests) is accompanied by the decrease of the cross-section (width) of the mat:

$$
\Delta g=g-g^{\prime}=g-v \epsilon
$$

where: $g$ - original mat width; $g^{\prime}$ - width after deformation; $\epsilon=$ $=\Delta L / L$ is a unitary longitudinal deformation; $v$ - transverse expansion coefficient.

Tearing horizontal forces, originating from tensions of horizontal pressure in the loaded soil, may have certain influence on the change of element $\Delta g$. These forces are partially taken over by the unwoven fabric in the form of friction. The change of $\Delta g$ depends, among others, on the following elements:
- settlement caused by durable changes in the soil layer (sealing of layer);

- settlement, as a result of elastic deformations of soil grain arrangement.

The value of $\Delta g$ may be a durable deformation, partially or totally elastic. The degree of the mat "pressing" $\Delta g$ depends, among others, on the quantity and distribution of the plates. The influence of unwoven fabric on the lateral pressure reduction and on the change of pressure graph course was observed, depending on the quantity and distribution of these plates. Yet, the effects of unwoven fabric (in the quantative sense) are less considerable than, for example, of a steel grid, for which the pressure reduction was achieved by approx. $50 \%$. Only the triple layer of unwoven fabric secures the lateral pressure reduction by approx. $31 \%$. The qualitative phenomena proceed similarly as for the effect of steel grids or geo-grids, because the zonal reduction of pressure ordinates also occurs. However, most frequently the maximum reduction of the pressure ordinate takes place below the level of mat location, since the unwoven fabric settled by this value in the first phase of work under the load from the soil overlay (see Fig. 1).

The vertical pressures of soil samples (sand) on the modelled subsoil (vertical tensions on the container bottom from the soil layer weight and external load) were measured in central axes $x, y$ of the container bottom. The value and distribution of these pressures is a function of many variables, thus it depends, among others, on:

- type of soil layer (i.e. on graining from which the value of the interior pressure angle results),

- level of soil layer consolidation (which determines the value of the interior pressure angle),

- type of external load (static, dynamic) and load geometry and load history,

- reinforcement parameters (e.g. material, number of plates, distribution).

$\begin{array}{lllllllllll}0,24 & 0,18 & 0,12 & 0,06 & 0,00 & 0,06 & 0,12 & 0,18 & 0,24\end{array}$

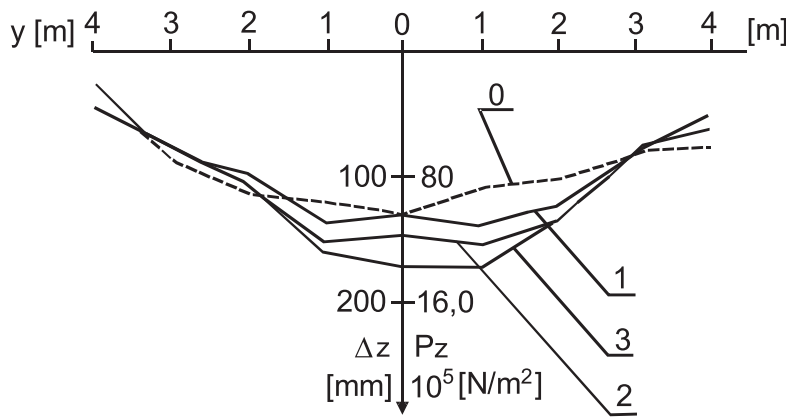

Fig. 2 Chart of vertical pressures on the soil. Sand reinforced with triple unwoven fabric Terratex 600 at changeable depth [6, 7].

Load 0,19 MPa, cycle I of load. Symbols: 0 - no reinforcement;

1 - reinforcement at the depth of $z_{2}=0,09 \mathrm{~m} ; 2$ - reinforcement at the depth of $z_{4}=0,21 \mathrm{~m} ; 3-$ reinforcement at the level of $z_{6}=0,33 \mathrm{~m}$. 
The changeability of pressures on the soil is closely connected with a global (spatial) level of soil sample tension, i.e. with the variability of lateral pressure. The chart of vertical pressures on

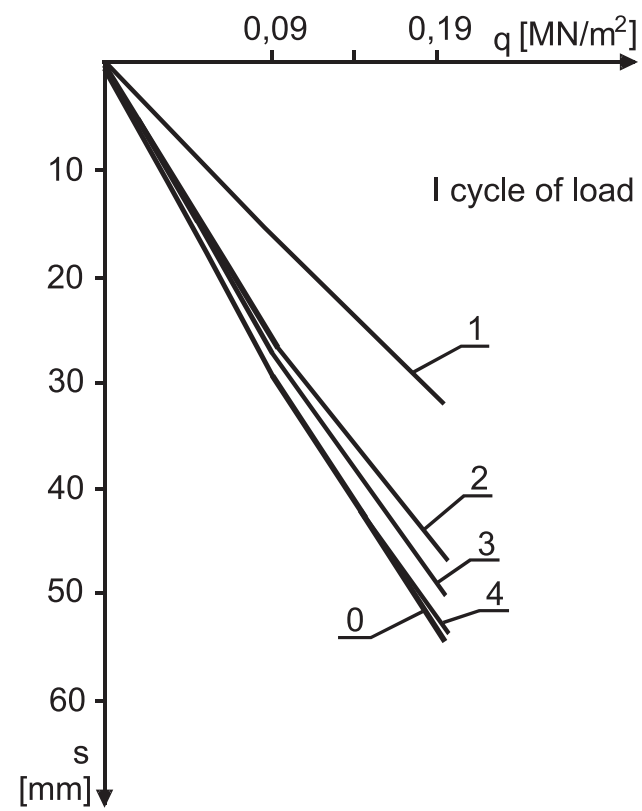

Fig. 3 Vertical deformations of sand samples reinforced with unwoven fabrics [6, 7]. Symbols in the text.

the soil for sand reinforced with triple unwoven fabric Terratex 600 situated on the changeable depth is presented in Fig. 2. Fig. 3 illustrates vertical deformations for models with identical reinforcement (at load of 0,19 Mpa). The mean from vertical relocations was accepted as a measure of vertical deformations; the vertical relocations were measured in four corners of a loading plate with dimensions in the plan $0,315 \times 0,315 \mathrm{~m}$.

\section{Soil layer reinforced with geo-grids}

Mean pressures on the modelled soil (expressed by mean vertical relocation $\Delta z_{s r}$ of sensors of the container bottom with a soil sample) in the function of load is presented in Fig. 4. The charts have been worked out for selected cases of reinforcement and comparatively for the standard.

As we can see in the drawing, the pressures increase linearly in reinforced and not reinforced sand, together with the increase of load up to the value which is accompanied by active boundary level of pressure. Fig. 5 shows the distribution of vertical pressures on the bottom (measured in one of main central axes of bottom surface) for selected cases of reinforced and not reinforced soil.

Table 1 presents the results of measurements of mean pressures on the soil for selected cases of sample reinforcement and comparatively for the standard. The comparison was conducted with stable load $q_{\max }$.

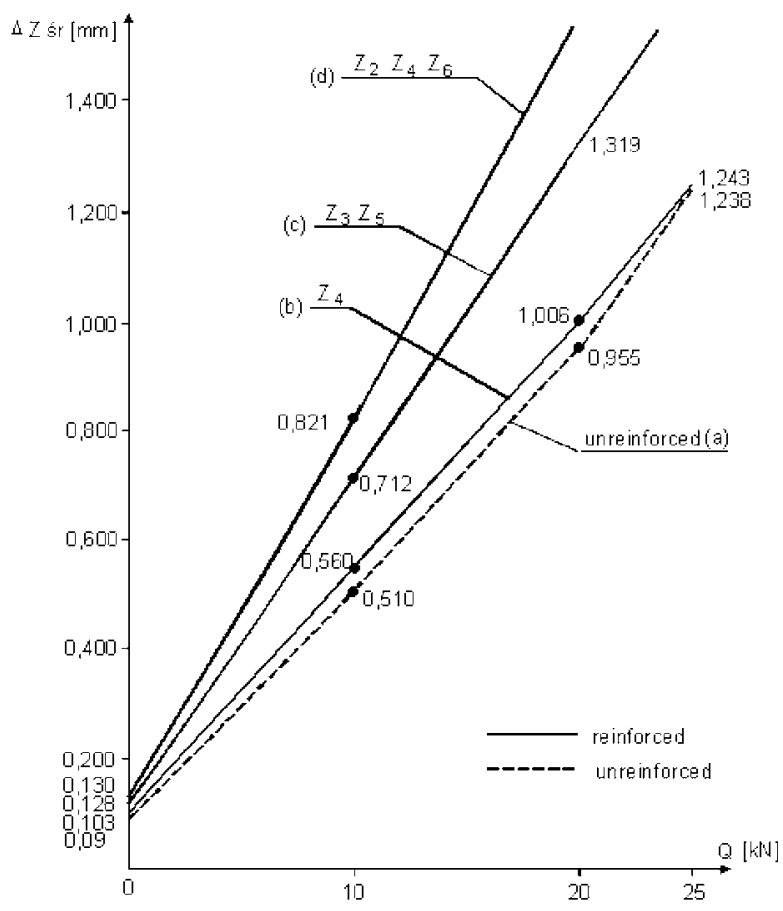

Fig. 4 Chart of vertical pressures on the soil in the function of load [6, 7]: $a$ - standard; $b$ - single reinforcement at level 4;

$c$ - reinforcement with two plates at levels 3 and 5 $d$ - reinforcement with three plates 2,4 i 5 .

\section{Condition of tension equilibrium in reinforced soil model and coefficient of pressure transmission to the soil}

The variability of pressures $\sigma_{z}$ on the soil is closely connected with the variability of lateral pressure (i.e. horizontal deformability controlled directly with reinforcement):

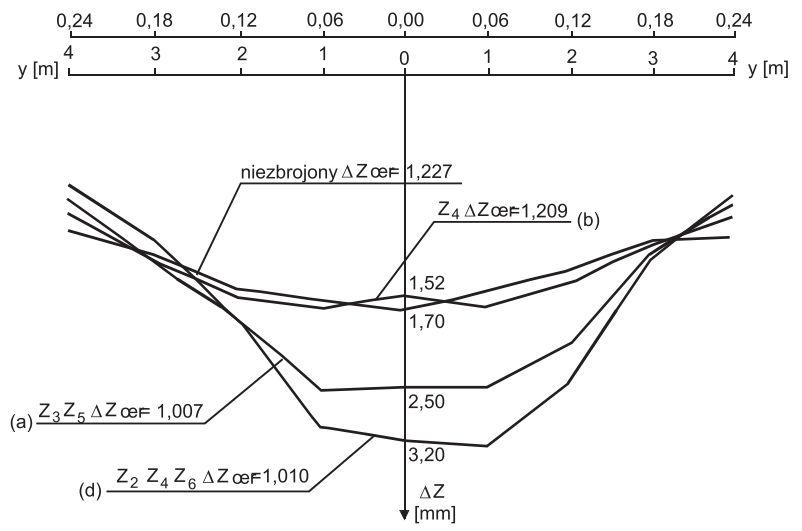

Fig. 5 Distribution of vertical pressures of the layer on the subsoil along axis y [6, 7]. a - not reinforced (standard); $b$ - reinforcement with single grid; $c$ - reinforcement with two grids; $d$-reinforcement with three grids. 
Mean pressures on the subsoil for selected cases of soil sample reinforcement, with maximum load $q_{\max }=0.24 \mathrm{Mpa}$

\begin{tabular}{|c|c|c|c|}
\hline $\begin{array}{c}\text { Reinforcement } \\
\text { distribution }\end{array}$ & $\begin{array}{c}\text { Total lateral } \\
\text { pressure } \\
{[\%]}\end{array}$ & $\begin{array}{c}\text { Maximum } \\
\text { pressures on } \\
\text { subsoil } \\
\text { patm }\end{array}$ & $\begin{array}{c}\text { Medium } \\
\text { pressures on } \\
\text { subsoil } \\
\Delta z_{\text {med }}[\mathrm{mm}]\end{array}$ \\
\hline pattern & 100 & 1.700 & 1.238 \\
\hline $\mathrm{Z}_{4}$ & 54.1 & 1.520 & 1.243 \\
\hline $\mathrm{Z}_{3}-\mathrm{Z}_{6}$ & 33.6 & 2.580 & 1.614 \\
\hline $\mathrm{Z}_{2}-\mathrm{Z}_{4}-\mathrm{Z}_{6}$ & 23.6 & 3.200 & 1.805 \\
\hline
\end{tabular}

$$
\sigma_{z}^{*}=f\left(\sigma_{x}^{*}, \sigma_{y}^{*}\right)
$$

where: $\left(\sigma_{x}^{*}, \sigma_{y}^{*}\right.$ - unitary lateral pressure in the directions of main axes of a co-ordinate system of base $x, y$.

The mean value of pressures $\sigma_{z}$ can be calculated using the elementary method from the equation of equilibrium of forces acting on the soil sample (Fig. 6) considering the technical conditions of the testing facility. This equation acquires the following form for the standard sample:

$$
q F_{p l}-\sigma z_{s r} F_{d}-s_{s r} 4 F_{s}=0
$$

where:

$\mathrm{q}[\mathrm{kPa}]$ - unitary vertical load,

$F_{p l}\left[\mathrm{~m}^{2}\right]$ - loading plate surface,

$\sigma z_{s r}[\mathrm{kPa}]-$ mean pressure of soil sample on the modelled singleparameter subsoil,

$F_{d}\left[\mathrm{~m}^{2}\right]$ - surface of container bottom with soil,

$s_{s r}=f_{s} \sigma z_{s r}[\mathrm{kPa}]$ - mean unitary friction force between the soil and inner areas of container walls,

$f_{S} \quad$ - coefficient of friction between the soil layer and inner area of container walls (as it is provided in a chapter concerning a test stand, the layer-wall contact is indirect: through two layers of PCV foil separated with bearing grease in order to decrease the value of $f_{S}$ coefficient),

$\sigma z_{s r}[\mathrm{kPa}]-$ mean lateral pressure of the layer in the direction of horizontal axes,

$F_{s}\left[\mathrm{~m}^{2}\right] \quad$ - surface of container wall.

Equation (3) for soil sample with reinforcement has the following form:

$$
q F_{p l}-\sigma z_{s r}^{*} F_{d}-f_{s} \sigma z_{s r}^{*}\left(4 F_{s}\right)=0
$$

As it is known from experiments, in the reinforced soil:

$$
\sigma z_{s r}^{*}<\sigma z_{s r}
$$

and

$$
\sigma z_{s r}^{*}>\sigma z_{s r}
$$

The inequality (6) results from considerations over equation (4) after accepting condition (5). Because of the above, the following functional dependence for reinforced soil can be formulated:

$$
\sigma z_{s r}^{*}=f(\alpha, \beta, \gamma)=f(\lambda)
$$

where: $\alpha$ - reinforcement rigidity, $\beta$ - number of plates (quantity of reinforcement), $\gamma$ - reinforcement distribution. The vertical range of anisotropic cohesion, which the soil sample receives as a result of reinforcement, is connected with these three parameters.

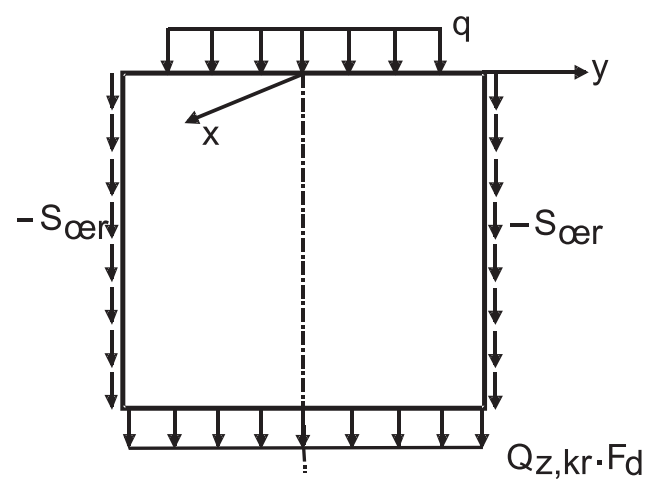

Fig. 6. Scheme for the static analysis of the soil sample work [6,7].

One of the parameters, characterising the work of loaded noncohesive soil layer, is the coefficient of pressure transfer to the subsoil. It was introduced by S. Mazur [2] on the basis of test results of vertical tensions transmitted through a layer $0.10 \mathrm{~m}$ thick; 0.20 and $0.30 \mathrm{~m}$ of basalt breakstone $20 / 60$. It is specified as a ratio of observed value of pressure on the subsoil to mean values of pressures transmitted to the soil layer:

$$
W_{p}=\sigma_{z, \max }\left(\sigma_{0}\right)^{-1}
$$

where: $\sigma_{z, \max }$ - the highest pressure on the subsoil,

$\sigma_{0} \quad$ - unitary pressure of a panel loading the soil layer.

Coefficient $W_{p}$ is approximately a stable value for a given type of a soil layer and a specified area transferring the load, in case of a layer $0.30 \mathrm{~m}$ thick.

\section{Conclusion}

The dependence of mean values of horizontal pressures of a soil layer from elastic flexibility of a modelled subsoil was observed (in specified conditions of laboratory representation). The highest pressure value is achieved at rigid subsoil. The differences of flexibility of the order of $5010^{-6} \mathrm{~N} / \mathrm{m}^{3}$ do not influence the value of horizontal pressures in an unquestionable way. The subsoil hardening $(C p=\infty)$ causes the increased displacement of the layer from under the panel, and in consequence also influences the increase of vertical deformations (settlement). 
The following parameters result from the analysis of the vertical pressure values of the layer:

- the values and distribution of the sample pressure on the subsoil are in given soil a function of load, number and distribution of reinforcement;

- a change of the pressure values at stable loading but variable parameters related to reinforcement (number of plates and distribution) takes place together with the change of the shape of a curve of their distribution on the surface of the container bottom;

- the variability of pressure values of the layer is closely connected with the variability of horizontal pressure, and in tested models it results from technical conditions of the test stand.

The reinforcement placed horizontally influences the increase of the load-carrying ability of the soil layer loaded vertically, through the reduction of vertical and horizontal deformations. The reduction of deformability denotes the improvement of strength parameters.

Less significant vertical deformations of the loaded soil are connected with the reduction of the horizontal pressure value. Horizontally located reinforcement partially takes over the forces of soil horizontal pressure.

Laboratory tests of lateral pressure of the loaded reinforced soil, carried out at an original stand, enabled the control of variable factors operation, concerning the soil layer and reinforcement as well as establishing general regularities related to the behaviour of two-component composites (consisting of materials with extremely different mechanical properties: soil layer - reinforcement plates) at static loading.

\section{References}

[1] LONG N.T.: Badania gruntów zbrojonych [Tests of reinforced soils]. W: Wybrane zagadnienia geotechniki [Selected issues of geotechnics], PAN-IBW, Ossolineum, Wrocław 1978, s. 185-210.

[2] MAZUR S.: Wybrane zagadnienia nośności nawierzchni kolejowej [Selected issues of load-carrying ability of track structure], Prace Nauk. Instytutu Inżynierii Lądowej P.Wr. [Scientific Papers of the Institute of Civil Engineering], Nr 27, Seria: Monografie, Wrocław 1983

[3] SAWICKI A.: Statyka konstrukcji z gruntu zbrojonego [Statics of structures made of reinforced soil]. IBW-PAN, Gdańsk 1999.

[4] SCHLOSSER F.: JACOBSON H. M., JURAN J., Soil reinforcenment. Second Int. Conf. on geotextiles, Las Vegas 1982, s. 1158-1180.

[5] SUROWIECKI A.: Arbeit der bewehrten Sandschicht unter Dauerbelastung. Tiefbau Ingenieurbau Strassenbau, Nr 3, 1988, s. 130-135.

[6] SUROWIECKI A.: Laborversuche zum Einfluss ausgewaehlter Parameter auf die Wirkung der Bewehrung in lockeren Boeden. Bauingenieur, $\mathrm{Nr}$ 5, 1989, s. 215-217.

[7] SUROWIECKI A.: Laboruntersuchungen von mechanischen Eigenschaften bewehrter lockerer Bodenschichten. Bautechnik, 71, Heft 11, 1994, s. 707-711.

[8] SUROWIECKI A.: Badania modelowe sypkiego gruntu zbrojonego [Model testing of non-cohesive reinforced soil]. Drogownictwo [Highway engineering], Nr 7, 1994, s. 155-158.

[9] SUROWIECKI A.: Warunki wspótdziałania elementów gruntu zbrojonego [Conditions of co-operation of reinforced soil elements], Drogownictwo [Highway engineering], $\mathrm{Nr} 12,1997$, s.383-387. 